Proc. 13th International School on Theoretical Physics: Symmetry and Structural Properties of Condensed Matter

\title{
Experimental Investigation of Electrical Conductivity of Ethylene Glycol Containing Indium Oxide Nanoparticles
}

\author{
J. FAL ${ }^{a, *}$, M. WANIC $^{a}$, M. MALICKA $^{b}$, M. OLEKSY ${ }^{c}$ AND G. ŻYŁA ${ }^{a}$ \\ ${ }^{a}$ Department of Physics and Medical Engineering, Rzeszów University of Technology, Rzeszów, Poland \\ ${ }^{b}$ Applied Optics Division, Rzeszów University of Technology, Rzeszów, Poland \\ ${ }^{c}$ Department of Polymer Composites, Rzeszów University of Technology, Rzeszów, Poland
}

\begin{abstract}
Nanofluids as a quite new group of nanomaterials are very promising. A great potential of nanofluids was noted in second half of twentieth century and it was related with high increase of thermal conductivity. The most favourable effects of using nanofluids can be achieved in heat transfer systems, but also in other branch of industry like car, energy, and mining industry, even biomedicine industry. This paper presents results of experimental investigation of electrical conductivity of nanosuspension containing indium oxide nanoparticles dispersed in ethylene glycol. Five samples with volume fraction in the range $0.0016-0.0081$ were prepared using two-step method. After preparation, all samples were impatiently investigated in controlled temperatures in the range from $298.15 \mathrm{~K}$ to $333.15 \mathrm{~K}$. Measurement were conducted using conductivity meter MultiLine 3630 working with conductivity probe LR925/01 (WTW GmbH, Weilheim, Germany). Obtained results indicate that changes in volume concentration and temperature have strong impact on electrical conductivity of $\operatorname{In}_{2} \mathrm{O}_{3}-\mathrm{EG}$ nanofluids.
\end{abstract}

DOI: 10.12693/APhysPolA.135.1237

PACS/topics: indium oxide, ethylene glycol, nanofluids, electrical conductivity

\section{Introduction}

Last twenty years brought a lot of new advanced materials including polymers, composites, and nanomaterials with many potential applications. Some of these materials are nanofluids, defined as suspensions of solid particles with nanometric size at least in one dimension in base fluid. The most commonly used base fluids are ethylene glycol, water, and oils (both synthetic and natural). These types of fluids are preferred by researchers, because of the universality of their application in many technological solutions. Modification of base fluids by nanoparticles change their physical properties. From the point of view of practical applications the key parameters are thermal conductivity and viscosity. Since the discovery of the nanofluids, many papers on their thermal properties have been published up to now. Wide overview of these papers can be found in a few review papers [1-3]. Generally, addition of nanoparticles to base fluids causes improvement in thermal conductivity, but also has negative effect on other properties such as viscosity, which is equally important in context of practical use of nanofluids. Rheological properties of this type of fluids are also intensively investigated by researchers. Many review papers $[3,4]$ were published where authors present comparison of rheological properties of various types of nanofluids. Another type of properties of nanofluids, which are poorly studied by researchers are electrical conductivity [5,6], optical properties [7], breakdown voltage $[8,9]$, dielectric properties $[10]$, and surface tension [11].

*corresponding author; e-mail: jacekfal@prz.edu.pl
This paper focuses on electrical properties of ethylene glycol (EG) based nanofluids containing indium oxide $\left(\mathrm{In}_{2} \mathrm{O}_{3}\right)$ nanoparticles.

\section{Materials and methods}

\subsection{Materials and sample preparation}

For preparation of nanosuspensions of indium oxide in ethylene glycol commercially available nanoparticles were used. According to the manufacturer, PlasmaChem $\mathrm{GmbH}$ (Berlin, Germany), the average particle size of $\mathrm{In}_{2} \mathrm{O}_{3}$ nanopowder is $4 \mathrm{~nm}$, and it was confirmed by $\mathrm{A}$ JEOL JSM-6700F (JEOL, Tokyo, Japan) field emission scanning electron microscope (SEM) investigation as presented in Fig. 1. SEM pictures show that nanoparticles show tendency to agglomerate.

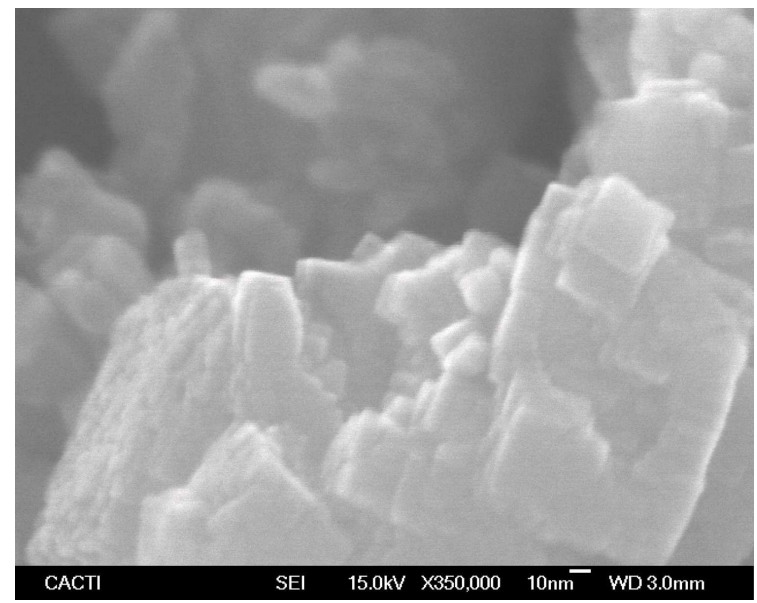

Fig. 1. SEM image of dry $\operatorname{In}_{2} \mathrm{O}_{3}$ nanoparticles. 
Five samples with volume fraction $\left(\varphi_{v}\right)$ from 0.0016 to 0.0081 were prepared using two-step method. Fraction higher than 0.0081 ( $5 \%$ by mass) exhibit significant increase in viscosity, which is not favourable from the viewpoint of practical application.

First, necessary amount of nanoparticles and ethylene glycol was weighted using analytical balance (WAS 220/X, Radwag, Radom, Poland), then mixed for $30 \mathrm{~min}$ using Genius 3 Vortex (IKA, Staufen, Germany). In the last step of preparation, samples were treated by ultrasounds in water bath Emmi $60 \mathrm{HC}$ (EMAG, MoerfeldenWalldorf, Germany) for $200 \mathrm{~min}$.

\subsection{Measuring method}

Electrical conductivity $(\sigma)$ of $\operatorname{In}_{2} \mathrm{O}_{3}-\mathrm{EG}$ nanosuspension was measured by conductivity meter MultiLine 3630 working with LR 925/01 conductivity probe (WTW GmbH, Weilheim, Germany) in the range of $0.01-$ $200 \mu \mathrm{S} \mathrm{cm}^{-1}$ with $0.01 \mu \mathrm{Scm}^{-1}$ resolution and accuracy better than $1 \%$ for values over $1 \mu \mathrm{S} \mathrm{cm}^{-1}$ which was confirmed in previous paper [12]. Conductivity meter with this configuration allows to measure simultaneously both electrical conductivity and temperature. Temperature was changed in the range from $298.15 \mathrm{~K}$ to $333.15 \mathrm{~K}$ with $5 \mathrm{~K}$ step, and accuracy of $0.2 \mathrm{~K}$. To control temperature of sample the self made chamber connected with thermostat circulator Hanon FCL6-20 (Hanon Instruments, Jinan, China) was employed.

\section{Results and discussion}

Experimental results of electrical conductivity and its enhancement of $\mathrm{In}_{2} \mathrm{O}_{3}-\mathrm{EG}$ nanofluids for five samples with various volume fraction of nanoparticles in base fluid and pure base fluid were presented in Figs. 2 and 3 and summarized in Table I.

Based on these data it might be noted that both mass fraction and temperature have significant impact on electrical properties of $\mathrm{In}_{2} \mathrm{O}_{3}-\mathrm{EG}$ nanofluids, however, it should be noted that volume fraction effect is higher and more visible than temperature, which is shown in Fig. 4.

Increase in volume fraction of nanoparticles in ethylene glycol up to 0.0081 causes increase in electrical conductivity enhancement for all tested temperatures.

The highest increase in electrical conductivity for $\mathrm{In}_{2} \mathrm{O}_{3}-\mathrm{EG}$ nanofluids was achieved for 0.0081 vol. $\%$ at temperature of $333.15 \mathrm{~K}$ and it was 272 times higher than that in case of pure ethylene glycol at 298.15 K. Enhancement in electrical conductivity for indium oxide nanofluids with $1 \%$ volume concentration and various content of PVP as surfactant was also reported by Latha et al. [13]. They observed increase in electrical conductivity with increasing content of polymer (PVP) at room temperature. As revealed by Ganguly et al. [14], increase in electrical conductivity in nanofluids can be related with creating electrical double layer around nanoparticles, which can help in the transport of electric charge carriers.

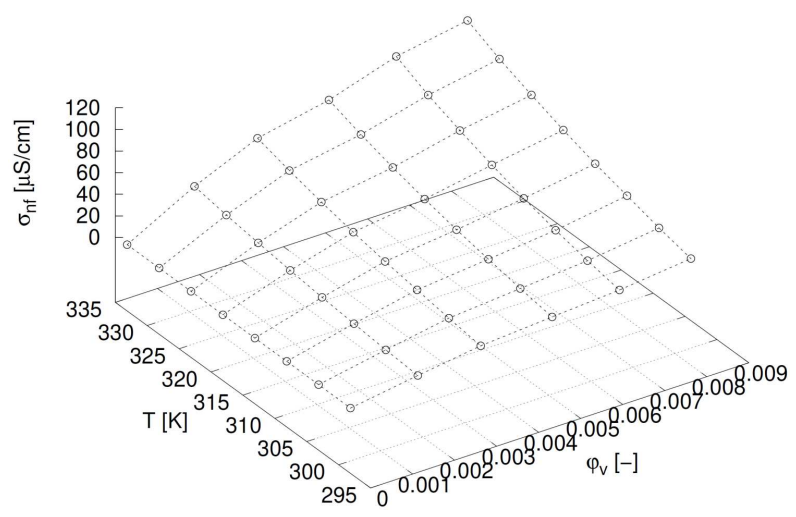

Fig. 2. Dependence of electrical conductivity of $\mathrm{In}_{2} \mathrm{O}_{3}-\mathrm{EG}$ nanofluids on temperature and volume fraction.

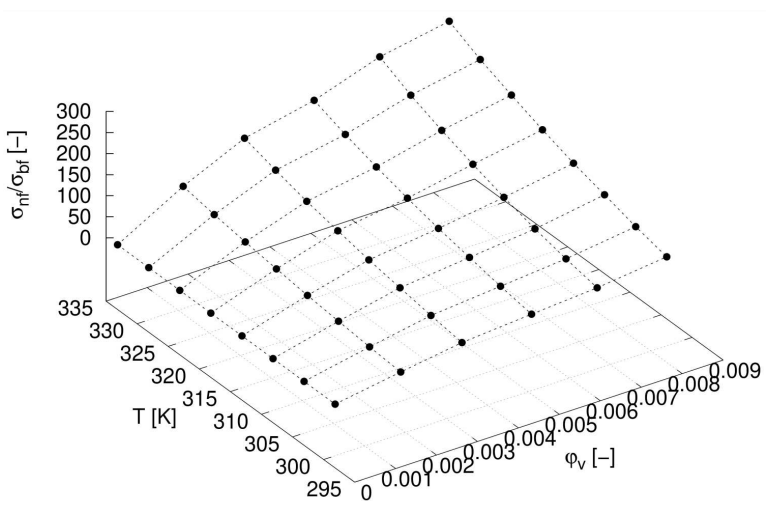

Fig. 3. Dependence of electrical conductivity enhancement of $\mathrm{In}_{2} \mathrm{O}_{3}-\mathrm{EG}$ nanofluids on temperature and volume fraction.
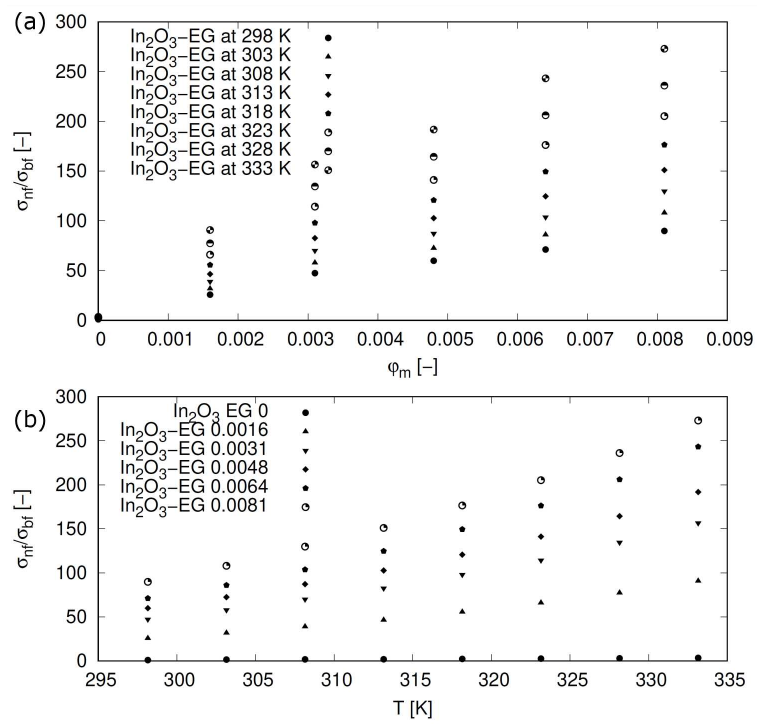

Fig. 4. Dependence of electrical conductivity enhancement of $\mathrm{In}_{2} \mathrm{O}_{3}$-EG nanofluids on (a) volume fraction for various temperatures, (b) on temperature for various volume fractions. 
TABLE I

Electrical conductivity and their enhancement of $\mathrm{In}_{2} \mathrm{O}_{3}-\mathrm{EG}$ nanofluids for various volume fractions and temperatures.

\begin{tabular}{|c|c|c|c|c|c|c|c|c|c|}
\hline \multirow{2}{*}{$\varphi_{m}[-]$} & \multirow{2}{*}{$\varphi_{v}[-]$} & \multicolumn{8}{|c|}{ Temperature } \\
\hline & & $298.15 \mathrm{~K}$ & $303.15 \mathrm{~K}$ & $308.15 \mathrm{~K}$ & $313.15 \mathrm{~K}$ & $318.15 \mathrm{~K}$ & $323.15 \mathrm{~K}$ & $328.15 \mathrm{~K}$ & $333.15 \mathrm{~K}$ \\
\hline \multicolumn{10}{|c|}{ Electrical conductivity $\left[\mu \mathrm{S} \mathrm{cm}^{-1}\right]$} \\
\hline 0.00 & 0.0000 & 0.38 & 0.58 & 0.67 & 0.74 & 0.86 & 0.99 & 1.15 & 1.32 \\
\hline 0.01 & 0.0016 & 9.86 & 12.15 & 14.89 & 17.77 & 21.27 & 25.25 & 29.60 & 34.72 \\
\hline 0.02 & 0.0031 & 18.11 & 22.14 & 26.82 & 31.61 & 37.49 & 43.74 & 51.50 & 59.93 \\
\hline 0.03 & 0.0048 & 22.92 & 27.73 & 33.38 & 39.29 & 46.18 & 53.99 & 62.92 & 73.37 \\
\hline 0.04 & 0.01 & 27.21 & 32.92 & 39.69 & 47.71 & 57.20 & 67.46 & 67.46 & 93.07 \\
\hline 0.05 & 0.0081 & 34.35 & 41.35 & 49.69 & 57.80 & 67.55 & 78.54 & 90.32 & 104.47 \\
\hline \multicolumn{10}{|c|}{ Electrical conductivity enhancement [-] } \\
\hline 0.00 & 0.0000 & 1.00 & 1.53 & 1.76 & 1.94 & 2.24 & 2.59 & 3.02 & 3.46 \\
\hline 0.01 & 0.0016 & 25.76 & 31.74 & 38.90 & 46.43 & 55.58 & 65.96 & 77.34 & 90.71 \\
\hline 0.02 & 0.0031 & 47.33 & 57.84 & 70.07 & 82.59 & 97.96 & 114.28 & 134.56 & 156.58 \\
\hline 0.03 & 0.0048 & 59.88 & 72.45 & 87.22 & 102.66 & 120.67 & 141.07 & 164.39 & 191.71 \\
\hline 0.04 & 0.0064 & 71.09 & 86.01 & 103.71 & 124.66 & 149.45 & 176.27 & 176.27 & 243.18 \\
\hline 0.05 & 0.0081 & 89.76 & 108.03 & 129.83 & 151.02 & 176.48 & 205.20 & 235.99 & 272.97 \\
\hline
\end{tabular}

\section{Conclusions}

Experimental investigation of electrical properties of indium oxide ethylene glycol nanofluids with various volume fraction in temperature range from $298.15 \mathrm{~K}$ to $333.15 \mathrm{~K}$ was performed. Obtained results clearly indicate that both volume fraction and temperature affect the electrical conductivity and its enhancement. The maximum increase in electrical conductivity of $\mathrm{In}_{2} \mathrm{O}_{3}-\mathrm{EG}$ nanofluids was observed for 0.0081 volume fraction at $333.15 \mathrm{~K}$ and it was approximately $27300 \%$.

\section{Acknowledgments}

The authors wish thank Luis Lugo and Javier P. Vallejo (University of Vigo, Spain) for SEM picture of nanoparticles.

\section{References}

[1] R. Sarviya, V. Fuskele, Mater. Today Proc. 4, 4022 (2017).

[2] M.M. Tawfik, Renew. Sustain. Energy Rev. 75, 1239 (2017).
[3] F. Jabbari, A. Rajabpour, S. Saedodin, Chem. Eng. Sci. 174, 67 (2017).

[4] S.S. Murshed, P. Estellé, Renew. Sustain. Energy Rev. 76, 1134 (2017).

[5] M.A. Rahman, M.A.N. Shatez, K.Y.N. Ritee, P. Yasmin, M.S. Hossain, M.Z.H. Khan, Int. J. Nano Biomater. 7, 102 (2017).

[6] G. Żyła, J. Fal, Thermochim. Acta 637, 11 (2016).

[7] O. Mahian, A. Kianifar, S.A. Kalogirou, I. Pop, S. Wongwises, Int. J. Heat Mass Transf. 57, 582 (2013).

[8] J. Fal, O. Mahian, G. Żyła, Energies 11, 2942 (2018).

[9] F. Ahmad, A.A. Khan, Q. Khan, R. Hussain, IEEE Access 7, 13396 (2019).

[10] M.A.K. Abdelhalim, M.M. Mady, M.M. Ghannam, Lipids Health Disease 10, 1 (2011).

[11] P. Estellé, D. Cabaleiro, G. Żyła, L. Lugo, S.S. Murshed, Renew. Sustain. Energy Rev. 94, 931 (2018).

[12] J. Fal, A. Sidorowicz, G. Żyła, Acta Phys. Pol. A 132, 146 (2017).

[13] C.K. Latha, Y. Aparna, R. Merugu, D. Ravinder, Int. J. Eng. Res. Appl. 6, 94 (2016).

[14] S. Ganguly, S. Sikdar, S. Basu, Powder Technol. 196 326 (2009). 